\title{
Voronoi Polyhedra as a Tool for the Characterization of the Inhomogeneous distribution in 1-butyl-3-methylimidazolium Cation based Ionic Liquids
}

Volodymyr Koverga ${ }^{1,2}$, Nishith Maity ${ }^{1}$, François Alexandre Miannay ${ }^{1}$,Oleg Kalugin ${ }^{3}$, Akos Juhasz $^{4}$, Adam Świątek, ${ }^{5}$ Kamil Polock ${ }^{5}$, Toshiyuki Takamuku ${ }^{6}$, and Pál Jedlovszky ${ }^{7 *}$, Abdenacer Idrissi, ${ }^{1 *}$

${ }^{1}$ Laboratoire de Spectrochimie Infrarouge et Raman (UMR CNRS A8516), Université de Lille, Science et Technologies, 59655 Villeneuve d'Ascq Cedex, France

${ }^{2}$ Institut des Sciences Analytiques et de Physico-Chimie pour l'Environnement et les Matériaux (IPREM), Université de Pau et des Pays de l'Adour. Technopôle Helioparc, 2, Avenue Pierre Angot, 64053, Pau Cedex 9, Nouvelle Aquitaine, France

${ }^{3}$ Department of Inorganic Chemistry, V.N. Karazin Kharkiv National University, Svoboda sq.,4, Kharkiv, 61022, Ukraine

${ }^{4}$ Semmelweis University, Department of Biophysics Radiation Biology, Laboratory of Nanochemistry, Budapest, Nagyvárad tér 4, 1089, Hungary

${ }^{5}$ Laboratory of Intermolecular Interactions Department of Chemistry University of Warsaw ul. Żwirki i Wigury 101 02-\&a 089 Warsaw, Poland

${ }^{6}$ Department of Chemistry and Applied Chemistry, Faculty of Science and Engineering, Saga University, Honjo-machi, Saga 840-8502, Japan

${ }^{7}$ Department of Chemistry, Eszterházy Károly University, Leányka utca 6, H-3300 Eger, Hungary

*Electronic mail: nacer.idrissi@univ-lille.fr (A. I.), jedlovszky.pal@ uni-eszterhazy.hu (P.J.) 
As it is shown in table S1, the calculated values of the density and the enthalpy of vaporization show satisfactory agreement with those reported in literature as well as with experimental ones . Similar observations also concern the calculated transport properties. The calculated values of $D$ are within $20 \%$ of experimental results in the systems studied. Moreover, the values reported in Table S1 shows in accordance to the experimental data that the cations diffuse faster than anions that also agreed with the observations for other imidazolium-based ILs. For the calculated viscosities the observed trend follows the sequence $\mathrm{C}_{4} \mathrm{mimPF}_{6}>\mathrm{C}_{4} \mathrm{mimBF}_{4}>\mathrm{C}_{4}$ mimTFO $>\mathrm{C}_{4}$ mimTFSA which is in good agreement with experiment. Such behavior of viscosity was attributed to the difference in the shape and symmetry of anion, where the ILs with highly symmetric, nearly spherical anions found to be more viscous. This order for different anions could be also depend from the strength of the Hbonding interactions between cation and anion as well as to their electrostatic interaction.

Furthermore, the comparison between the experimental and the calculated X-Ray structure factor for C4mimTFO and C4mimTFSAis illustrated in Fig. S1. This figure shows that the potential model to describe the ions interactions reproduce correctly the experimental data.
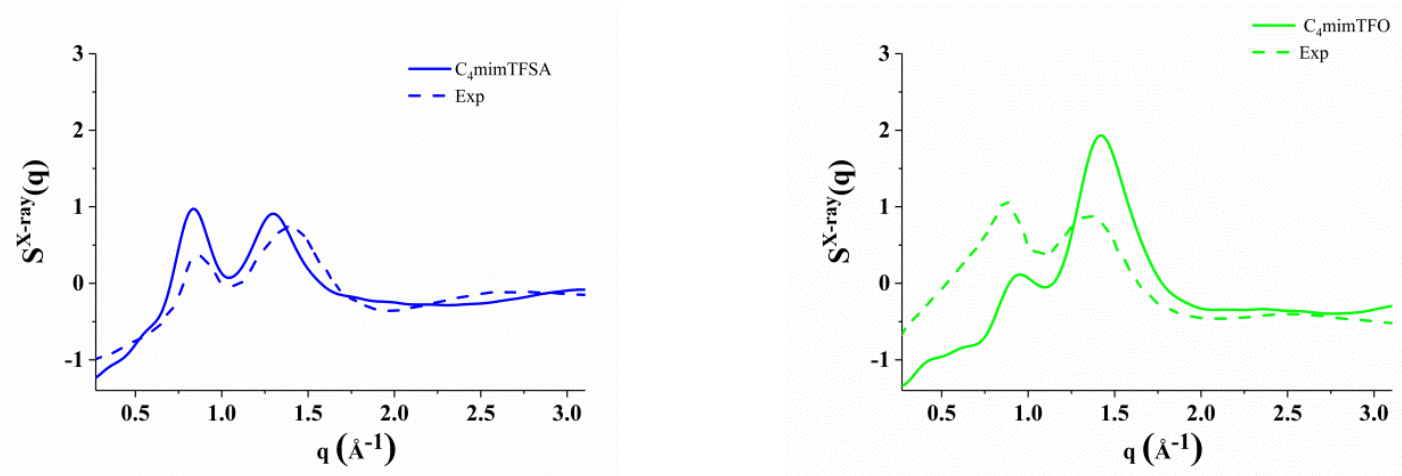

Fig. S1 Comparison between the calculated and experimental structure factors for C4mimTFSA and C4mimTFO. 
Table S1:. Observed density, $\rho$, enthalpy of vaporization, $\Delta H_{\text {vap }}$, self-diffusion coefficient, $D$, and share viscosity, $\eta$, calculated at $298.15 \mathrm{~K}$ for $\mathrm{C}_{4} \mathrm{mimBF}_{4}, \mathrm{C}_{4} \mathrm{mimPF}_{6}, \mathrm{C}_{4}$ mimTFO and $\mathrm{C}_{4}$ mimTFSA models in comparison with the literature data and experimental measurements.

\begin{tabular}{|c|c|c|c|}
\hline & this work & Literature $^{1}$ & experimental \\
\hline \multicolumn{4}{|c|}{$\rho / \mathrm{g} \mathrm{cm}^{-3}$} \\
\hline $\mathrm{C}_{4} \mathrm{mimBF}_{4}$ & 1.2130 & 1.2060 & $1.2020^{2}$ \\
\hline $\mathrm{C}_{4} \mathrm{mimPF}_{6}$ & 1.4085 & 1.3880 & $1.3680^{2}$ \\
\hline $\mathrm{C}_{4} \operatorname{mimTFO}$ & 1.3312 & 1.3170 & $1.2980^{2}$ \\
\hline $\mathrm{C}_{4} \operatorname{mimTFSA}$ & 1.4972 & 1.4460 & $1.4370^{2}$ \\
\hline \multicolumn{4}{|c|}{$\Delta H_{\text {vap }} / \mathrm{kJ} \mathrm{mol}^{-1}$} \\
\hline $\mathrm{C}_{4} \mathrm{mimBF}_{4}$ & 32.12 & 31.90 & $33.78^{3}$ \\
\hline $\mathrm{C}_{4} \mathrm{mimPF}_{6}$ & 32.84 & 33.00 & $37.00^{4}$ \\
\hline $\mathrm{C}_{4}$ mimTFO & 33.48 & 32.94 & $33.22^{5}$ \\
\hline $\mathrm{C}_{4} \operatorname{mimTFSA}$ & 31.33 & 31.23 & $32.17^{6}$ \\
\hline \multicolumn{4}{|c|}{$D 10^{5} / \mathrm{cm}^{2} \mathrm{~s}^{-1}$} \\
\hline $\mathrm{C}_{4} \mathrm{mim}^{+} / \mathrm{BF}_{4}^{-}$ & $0.0261 / 0.0210$ & $0.0230 / 0.0183$ & $\begin{array}{c}0.0180 / 0.0170^{2} \\
0.017 /-^{7} \\
0.016 / 0.015^{8} \\
0.0158 / 0.0146^{9}\end{array}$ \\
\hline $\mathrm{C}_{4} \mathrm{mim}^{+} / \mathrm{PF}_{6}^{-}$ & $0.0142 / 0.0094$ & $0.0105 / 0.0074$ & $\begin{array}{l}0.0089 / 0.0071^{2} \\
0.0078 / 0.0066^{7} \\
0.0080 / 0.0059^{8} \\
0.0071 / 0.0054^{9}\end{array}$ \\
\hline $\mathrm{C}_{4} \mathrm{mim}^{+} / \mathrm{TFO}^{-}$ & $0.0224 / 0.0172$ & $0.0208 / 0.0141$ & $\begin{array}{c}0.0210 / 0.0160^{2} \\
0.018 /-^{7} \\
0.019 / 0.014^{8}\end{array}$ \\
\hline $\mathrm{C}_{4} \mathrm{mim}^{+} / \mathrm{TFSA}^{-}$ & $0.0262 / 0.0178$ & $0.0270 / 0.0210$ & $\begin{array}{c}0.0340 / 0.0260^{2} \\
0.036 /-^{7} \\
0.0299 / 0.0238^{8} \\
0.0282 / 0.0216^{9}\end{array}$ \\
\hline \multicolumn{4}{|c|}{$\eta / \mathrm{mPa} \mathrm{s}$} \\
\hline $\mathrm{C}_{4} \mathrm{mimBF}_{4}$ & 76.2 & 71 & $\begin{array}{c}75.3^{2} \\
75.4^{10}\end{array}$ \\
\hline $\mathrm{C}_{4} \mathrm{mimPF}_{6}$ & 190.0 & 185 & $\begin{array}{l}182.4^{2} \\
209.1^{10} \\
209.2^{11}\end{array}$ \\
\hline $\mathrm{C}_{4} \operatorname{mimTFO}$ & 66.3 & 65 & $\begin{array}{l}65.4^{2} \\
63.2^{12} \\
64.2^{13}\end{array}$ \\
\hline $\mathrm{C}_{4} \operatorname{mimTFSA}$ & 43.3 & 42 & $\begin{array}{c}40.0^{2} \\
40.6^{10,14}\end{array}$ \\
\hline
\end{tabular}




\section{Refernces}

1. A. Mondal and S. Balasubramanian, J. Phys. Chem. B, 2014, 118, 3409-3422.

2. H. Tokuda, S. Tsuzuki, M. A. B. H. Susan, K. Hayamizu and M. Watanabe, J. Phys. Chem. B, 2006, 110, 19593-19600.

3. W.-G. Xu, L. Li, X.-X. Ma, J. Wei, W.-B. Duan, W. Guan and J.-Z. Yang, J. Chem. Eng. Data., 2012, 57, 2177-2184.

4. A. Deyko, S. G. Hessey, P. Licence, E. A. Chernikova, V. G. Krasovskiy, L. M. Kustov and R. G. Jones, Phys. Chem. Chem. Phys., 2012, 14, 3181-3193.

5. A. Deyko, K. R. J. Lovelock, J.-A. Corfield, A. W. Taylor, P. N. Gooden, I. J. VillarGarcia, P. Licence, R. G. Jones, V. G. Krasovskiy, E. A. Chernikova and L. M. Kustov, Phys. Chem. Chem. Phys., 2009, 11, 8544-8555.

6. D. H. Zaitsau, G. J. Kabo, A. A. Strechan, Y. U. Paulechka, A. Tschersich, S. P. Verevkin and A. Heintz, J. Phys. Chem. A, 2006, 110, 7303-7306.

7. B. A. Marekha, O. N. Kalugin, M. Bria, R. Buchner and A. Idrissi, J. Phys. Chem. B, 2014, 118, 5509-5517.

8. H. Tokuda, K. Hayamizu, K. Ishii, M. A. B. H. Susan and M. Watanabe, J. Phys. Chem. B, 2004, 108, 16593-16600.

9. D. Nama, P. G. A. Kumar, P. S. Pregosin, T. J. Geldbach and P. J. Dyson, Inorg. Chim. Acta, 2006, 359, 1907-1911.

10. J. Jacquemin, P. Husson, A. A. H. Padua and V. Majer, Green Chem., 2006, 8, 172180.

11. W. Fan, Q. Zhou, J. Sun and S. Zhang, J. Chem. Eng. Data., 2009, 54, 2307-2311.

12. M.-L. Ge, R.-S. Zhao, Y.-F. Yi, Q. Zhang and L.-S. Wang, J. Chem. Eng. Data., 2008, 53, 2408-2411.

13. K. R. Seddon, A. Stark and M.-J. Torres, in Clean Solvents, American Chemical Society, 2002, vol. 819, ch. 4, pp. 34-49.

14. S. Katsuta, Y. Shiozawa, K. Imai, Y. Kudo and Y. Takeda, J. Chem. Eng. Data., 2010, 55, 1588-1593. 